\title{
An increasing pathomorphism of pulmonary tuberculosis. Is there a therapeutic role for novel antimicrobial compounds effective on Mycobacterium tuberculosis?
}

\author{
Roberto Manfredi*, Sergio Sabbatani, Leonardo Calza \\ From $16^{\text {th }}$ International Symposium on HIV and Emerging Infectious Diseases \\ Marseille, France. 24-26 March 2010
}

\section{Background}

During recent $y$, a progressive emerging of tuberculosis (T) occurred, related to the overall increased age of general population, primary-secondary immunodeficiencies (including frequent-prolonged exsposure to immunosuppressive-cytotoxic treatments), surgical and intensive care supports, bone marrow-solid organ transplantation, and recent immigration of people coming from $\mathrm{T}$-endemic areas.

\section{Methods}

Since Jan 2006, we hospitalized 78 cases of pulmonary $\mathrm{T}$, in over $75 \%$ of cases occurred in patients $(\mathrm{p})$ immigrated from developing countries.

\section{Results}

In only $4 \mathrm{p}$ resistant or multiresistant (MDR) $\mathrm{T}$ strains were found, while 2 more $\mathrm{p}$ had a multi-resistant (XDR) T. Although enforcing all possible measures to increase p'adherence to treatments (empowerment, use of i.v. formulation whenever possible, delivery of oral drugs under direct control), over one third of $\mathrm{p}$ had a very slow clinical-radiological ameliorement (2-4 mo) (19 p of 78 even experienced an initial worsening during early treatment), with persistence of sputum and/ or bronchoalveolar lavage (BAL) fluid positive for Mycobacterium tuberculosis for over 2-4 mo (mean 2.3 $\pm 0.7 \mathrm{mo}$ ), during apparently adequate treatment. When excluding XDR-MDR $\mathrm{p}$, which had very prolonged admissions (sometimes over one y), and always deserved second-third-line drugs, in 8 more $\mathrm{p}$ we observed that off-label linezolid (L) adjunct together with at least 3 drugs with residual activity against $\mathrm{T}$, led to a rapid clinical-radiological improvement and negative microbiological search, with consequent possibility to achieve a protected discharge, supported by a sequential, oral therapy. L was also successfully employed in all $\mathrm{p}$ with XDR-MDR $\mathrm{T}$, when a temporarily negativization of respiratory secretions was achieved always and only after the L adjunct to a combination therapy selected on the ground of residual in vitro susceptibility assays.

\section{Discussion}

Notwithstanding the maintained, extensive microbiological susceptibility of $M$. tuberculosis strains responsible of the great majority of cases of pulmonary $\mathrm{T}$, an unexpected tendency of $\mathrm{p}$ to have a persistingly positive sputum/BAL and experience prolonged hospitalization for cure and isolation, has been recognized in the last y. No particularly suggestive chest imaging seems predictive of a so prolonged course, so that we presently lack of clinical-radiological elements predictive of this slow treatment response. The oxazolidinone $\mathrm{L}$ has an affordable activity against $M$. tuberculosis, and an extremely elevated intracellular concentration in respiratory tissues. The increasing microbiological, pharmacological, and clinical evidences may recommend the use as an offlabel salvage $\mathrm{L}$ treatment of pulmonary $\mathrm{T}$ refractory to treatment, although not necessarily determined by

* Correspondence: Roberto.manfredi@unibo.it

Infectious Diseases, University of Bologna, S. Orsola Hospital, Bologna, Italy 
resistant (MDR-XDR) strains. To rely on controlled data, randomized clinical trials including initially $\mathrm{p}$ with chemioresistant $\mathrm{T}$, are needed.

Published: 11 May 2010

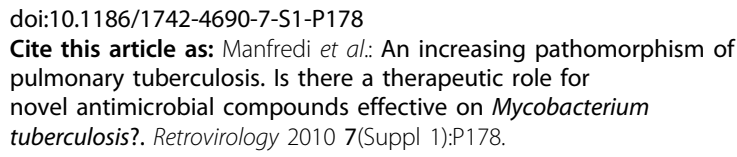

Submit your next manuscript to BioMed Central and take full advantage of:

- Convenient online submission

- Thorough peer review

- No space constraints or color figure charges

- Immediate publication on acceptance

- Inclusion in PubMed, CAS, Scopus and Google Scholar

- Research which is freely available for redistribution 